\title{
Quantitative proteomics reveals the effect of protein glycosylation in soybean root under flooding stress
}

\author{
Ghazala Mustafa ${ }^{1,2}$ and Setsuko Komatsu ${ }^{1,2 *}$ \\ Graduate School of Life and Environmental Science, University of Tsukuba, Tsukuba, Japan \\ ${ }^{2}$ National Institute of Crop Science, National Agriculture and Food Research Organization, Tsukuba, Japan
}

\section{Edited by:}

Dominique Job, Centre National de la Recherche Scientifique, France

\section{Reviewed by:}

Juan Antonio Vizcaino, European Bioinformatics Institute (European Molecular Biology Laboratory-EBI), UK

Wei Song, Max Planck Institute for Plant Breeding Research, Germany

\section{*Correspondence:}

Setsuko Komatsu, National Institute of Crop Science, National

Agriculture and Food Research

Organization, Kannondai 2-1-18,

Tsukuba 305-8518, Japan

e-mail: skomatsu@affrc.go.jp
Flooding stress has a negative impact on soybean cultivation because it severely impairs growth and development. To understand the flooding responsive mechanism in early stage soybeans, a glycoproteomic technique was used. Two-day-old soybeans were treated with flooding for 2 days and roots were collected. Globally, the accumulation level of glycoproteins, as revealed by cross-reaction with concanavalin A decreased by 2 days of flooding stress. Glycoproteins were enriched from total protein extracts using concanavalin A lectin resin and analyzed using a gel-free proteomic technique. One-hundred eleven and 69 glycoproteins were identified without and with 2 days of flooding stress, respectively. Functional categorization of these identified glycoproteins indicated that the accumulation level of proteins related to protein degradation, cell wall, and glycolysis increased, while stress-related proteins decreased under flooding stress. Also the accumulation level of glycoproteins localized in the secretory pathway decreased under flooding stress. Out of 23 common glycoproteins between control and flooding conditions, peroxidases and glycosyl hydrolases were decreased by 2 days of flooding stress. mRNA expression levels of proteins in the endoplasmic reticulum and $\mathrm{N}$-glycosylation related proteins were downregulated by flooding stress. These results suggest that flooding might negatively affect the process of $\mathrm{N}$-glycosylation of proteins related to stress and protein degradation; however glycoproteins involved in glycolysis are activated.

Keywords: soybean, flooding stress, root, proteomics, glycoproteins

\section{INTRODUCTION}

Climate change is potentially the greatest threat to biodiversity (Eigenbrod et al., 2014). The industrial revolution has resulted in elevated levels of carbon dioxide and other greenhouse gases that induce global warming and change precipitation patterns (Hao et al., 2010). Increasing climatological extremes lead to catastrophic loss of crop productivity (Bita and Greats, 2013). In these changing conditions, plants are under the effects of various abiotic stresses like drought (Manavalan et al., 2009), salinity (Parvaiz and Satyawati, 2008), cold (Beck et al., 2004, 2007), and high temperature (Bita and Greats, 2013). Flooding has devastating effects on crop growth and ultimately causes a reduction in crop production (Normile, 2008).

Soybean is an important legume crop due to its high protein content. Soybean is susceptible to flooding stress (Hou and Thseng, 1991), a major problem that affects its growth and yield around the world. The grain yield of this crop is particularly affected by this stress, notably during seed germination and early vegetative stages (Githiri et al., 2006). Early exposure of soybean plants to flooding stress causes severe damage due to rapid

Abbreviations: CBB, Coomassie brilliant blue; ConA, concanavalin A; LC, liquid chromatography; MS, mass spectrometry; ER, endoplasmic reticulum; qRT-PCR, quantitative reverse transcription polymerase chain reaction. imbibition of water by the cotyledons and destruction to the root systems (Nakayama et al., 2004). Its yield was estimated to be reduced to $25 \%$ due to flooding injuries in Asia, North America, and other regions of the world where soybean is rotated with rice in paddy fields. Oosterhuis et al. (1990) reported a reduction in soybean yield of $17-43 \%$ at the vegetative stage and $50-56 \%$ at the reproductive stage due to flooding stress. This stress leads to a shift to alternative pathways of energy generation. The shortage of oxygen under flooding stress results in a shift from aerobic to anaerobic respiration. A low diffusion rate of oxygen under flooding stress is a limiting factor for plant survival, and most plants die under limited oxygen supply (Voesenek et al., 2006).

The process of glycosylation is a complicated and highly important post-translational modification occurring in natural proteins. Protein glycosylation results from the covalent linkage of an oligosaccharide side chain to a protein moiety (Spiro, 2002). The vast majority of eukaryotic proteins are glycosylated. This protein modification plays an important role in protein folding, interaction, stability, and mobility, as well as in signal transduction (Roth et al., 2012). Glycosylated proteins are involved in many physiological functions and biological pathways (Pan et al., 2011; Ruiz-May et al., 2012). In plants, N-linked glycans have various roles including the prevention of proteolytic degradation, induction of correct folding, and biological activity of a protein. 
Along with this, they also contain targeting information and are involved in the protein recognition or cell-cell adhesion processes (Rayon et al., 1998). In animals, oligosaccharide-side chains act as targeting signal for lysosomal glycoproteins (Sly and Fischer, 1982). In plants, complex N-glycans confer important functions to secreted/secretory glycoproteins, such as protection of root growth from osmotic stress (von Schaewen et al., 2008).

Glycosylation is of two main types: $\mathrm{N}$-glycosylation and O-glycosylation. N-linked glycan biosynthesis starts at the cytosolic face of the endoplasmic reticulum (ER) where two $\mathrm{N}$-acetylglucosamine and five mannose residues are added sugar by sugar onto a dolichol carrier (Kornfeld and Kornfeld, 1985). In eukaryotes, several protein modifications, including the glycosylation reaction, occur in the ER (Abeijon and Hirscnberg, 1992). The ER is also responsible for various other cellular functions like protein folding, degradation, protein synthesis, lipid synthesis, and transfer (Coe and Michalak, 2010). Flooding has severe effects on ER function due to changes in the levels of calnexin, heat shock protein 70, and luminal binding protein (Nanjo et al., 2010). But the specific nature of these effects is still not clear. It has been reported that flooding stress causes damage to the ER and to the process of glycosylation (Komatsu et al., 2012). However, the relationships and interactions between different glycosylated proteins have not been fully characterized.

Because of its importance to cell functions, a comprehensive understanding of glycoproteins is of great importance to elaborate their roles and to understand plant responses to flooding stress. In this study, to understand the early responses of soybean roots to flooding stress, glycoproteins were analyzed from young soybean roots. For this purpose, the concanavalin A (ConA) lectin affinity method was used to target the glycoproteins (Yang and Hancock, 2004), and gel-free proteomics with liquid chromatography (LC) mass spectrometry (MS) was performed. ConA affinity chromatography was previously used to characterize the glycoproteome of tomato fruit (Catala et al., 2011) and in proteomic characterization of plant secreted proteins (Minic et al., 2007; Ligat et al., 2011). Furthermore, the mRNA expression levels of proteins in the ER and N-glycosylation related proteins were analyzed using quantitative reverse transcription-polymerase chain reaction (qRT-PCR).

\section{MATERIALS AND METHODS PLANT MATERIAL}

Seeds of soybean (Glycine max L. cv. Enrei) were sterilized with $1 \%$ sodium hypochlorite solution, rinsed in water, and sown on $500 \mathrm{~mL}$ silica sand with $150 \mathrm{~mL}$ water in a plastic case $(180 \times$ $140 \times 45 \mathrm{~mm})$. Soybean was grown in a growth chamber illuminated with white fluorescent light $\left(160 \mu \mathrm{mol} \mathrm{m}{ }^{-2} \mathrm{~s}^{-1}, 16 \mathrm{~h}\right.$ light period/day) at $25^{\circ} \mathrm{C}$ and $70 \%$ relative humidity. For ConA blotting, 2-day-old soybeans were flooded with water (Komatsu et al., 2010), for 1-4 days. For proteomics, 2-day-old soybeans were flooded for 2 days. For qRT-PCR, 2-day-old soybeans were flooded for 1 and 2 days. After treatments, roots were collected. Untreated plants were used as controls. Three independent experiments were performed as biological replicates for all experiments.

\section{PROTEIN EXTRACTION}

A portion $(500 \mathrm{mg}$ ) of samples was homogenized on ice using a mortar and pestle in buffer containing $20 \mathrm{mM}$ HEPES ( $\mathrm{pH} 7.5$ ), $150 \mathrm{mM} \mathrm{NaCl}, 1 \%$ Nonidet P-40, 0.25\% sodium deoxycholate, and $10 \%$ glycerol. The homogenate was centrifuged at $20,000 \times \mathrm{g}$ for $10 \mathrm{~min}$ at $4^{\circ} \mathrm{C}$. The supernatant was collected and centrifuged at $20,000 \times \mathrm{g}$ for $10 \mathrm{~min}$ at $4^{\circ} \mathrm{C}$ again. The supernatant was used as the total protein extract. Protein concentration was determined using the Bradford method (Bradford, 1976) with bovine serum albumin as the standard. For MS analysis, this total protein extract was purified as described below in the paragraph "Preparation of Proteins for Mass Spectrometry." For SDS-PAGE, 2x SDS sample buffer containing $120 \mathrm{mM}$ Tris- $\mathrm{HCl}$ (pH 6.8), 4\% SDS, $20 \%$ glycerol, and $10 \%$-mercaptoethanol was added in equal volume.

\section{GLYCOPROTEIN ENRICHMENT}

The extracted proteins were submitted to glycoprotein enrichment by using the glycoprotein isolation kit-ConA (Thermo Fisher Scientific, San Jose, CA, USA). All steps were performed at $25^{\circ} \mathrm{C}$. ConA resin was added to the spin column and centrifuged at $1000 \times \mathrm{g}$. Resin was rinsed three times with binding buffer provided in the kit. Before being applied to the ConA resin column, the protein samples were equilibrated with binding buffer. After 10 min of mixing, the resin was centrifuged at $1000 \times \mathrm{g}$. Resin was washed four times with binding buffer and then glycoproteins were eluted in SDS sample buffer containing $60 \mathrm{mM}$ Tris- $\mathrm{HCl}$ (pH 6.8), 2\% SDS, 10\% glycerol, and 5\% 2-mercaptoethanol. Protein concentration was determined using the Pierce $660 \mathrm{~nm}$ Protein Assay Reagent (Thermo Fisher Scientific) with bovine serum albumin as the standard.

\section{SDS-POLYACRYLAMIDE GEL ELECTROPHORESIS}

The proteins resulting from the total protein extract or from glycoprotein enrichment were separated by 17\% SDSpolyacrylamide gel electrophoresis. The electrophoresis was performed at a constant current of $20 \mathrm{~mA}$. After electrophoresis, the gels were stained for $1 \mathrm{~h}$ with Coomassie brilliant blue (CBB) (PhastGel $^{\mathrm{TM}}$ Blue R; GE Healthcare, Piscataway, NJ, USA) containing 30\% methanol and 10\% acetic acid, and then destained for $2 \mathrm{~h}$ in destaining solution containing $36 \%$ methanol and $10 \%$ acetic acid.

\section{CONCANAVALIN A BLOTTING}

For immunoblot analysis, proteins were separated by $17 \%$ SDSPAGE. After separation, proteins were transferred to a polyvinylidene difluoride membrane using a semidry transfer blotter. Blotted membrane was blocked overnight at $4^{\circ} \mathrm{C}$ in a buffer containing $20 \mathrm{mM}$ Tris- $\mathrm{HCl}$ ( $\mathrm{pH} 7.5$ ), $500 \mathrm{mM} \mathrm{NaCl}$, and 5\% nonfat milk (skim milk; Difco, Sparks, MD, USA) and incubated with a 1:2000 dilution of peroxidase-ConA antibody (Seikagaku, Tokyo, Japan), for $1 \mathrm{~h}$ at $25^{\circ} \mathrm{C}$. Glycoproteins were detected using an ECL plus Western blotting detection kit (GE Healthcare) following the manufacturer's protocol, and visualized by a luminescent image analyzer (Las-3000; Fujifilm, Tokyo, Japan). The relative band intensities were calculated using ImageJ software (http://imagej. nih.gov/ij/). 


\section{PREPARATION OF PROTEINS FOR MASS SPECTROMETRY}

For MS analysis, proteins $(100 \mu \mathrm{g})$ were purified by phase separation in the organic layer. In $100 \mu \mathrm{L}$ protein sample, $400 \mu \mathrm{L}$ methanol was added, and the resulting solution was mixed. After this, $100 \mu \mathrm{L}$ chloroform was added and mixed by vortexing. Then $300 \mu \mathrm{L}$ water was added to induce phase separation, mixed, and then centrifuged at $20,000 \times \mathrm{g}$ for $10 \mathrm{~min}$. The upper aqueous layer was discarded and $300 \mu \mathrm{L}$ methanol was added to the organic phase. The samples were centrifuged at 20,000 $\times \mathrm{g}$ for $10 \mathrm{~min}$. The resulting supernatant was discarded and the pellet was allowed to dry at $25^{\circ} \mathrm{C}$. The dried pellets were resuspended in $50 \mathrm{mM}$ ammonium bicarbonate and then reduced with $0.25 \mathrm{M}$ dithiothreitol for $1 \mathrm{~h}$ at $56^{\circ} \mathrm{C}$ and alkylated with $0.3 \mathrm{M}$ iodoacetamide for $1 \mathrm{~h}$ at $37^{\circ} \mathrm{C}$ in the dark. Alkylated proteins were digested with trypsin and lysyl endopeptidase (sequencing grade; Wako, Osaka, Japan) at 1:100 enzyme/protein concentration at $37^{\circ} \mathrm{C}$ for $16 \mathrm{~h}$. The resulting tryptic peptides were acidified with $10 \mu \mathrm{L}$ of $20 \%$ formic acid to $\mathrm{pH}<3$, desalted with a C18-pipette tip (NikkyoTechnos, Tokyo, Japan), and subjected to nanoLC MS/MS.

\section{DATA ACQUISITION BY MASS SPECTROMETRY}

Using an Ultimate 3000 nanoLC system (Dionex, Germering, Germany), peptides in $0.1 \%$ formic acid were loaded onto a C18 PepMap trap column $(300 \mu \mathrm{m}$ ID $\times 5 \mathrm{~mm}$, Dionex $)$. The peptides were eluted from the trap column and were separated using $0.1 \%$ formic acid in acetonitrile at a flow rate of $200 \mathrm{~nL} / \mathrm{min}$ on a C18 Tip column $(75 \mu \mathrm{m} \mathrm{1D} \times 120 \mathrm{~mm}$, NTTC-360/75-3, nanoLC capillary column (Nikkyo Technos) with a spray voltage of $1.5 \mathrm{kV}$. Peptides were analyzed on a nanospray LTQ XL Orbitrap MS (Thermo Fisher Scientific) operated in data-dependent acquisition mode with the installed Xcalibur software (version 2.0.7; Thermo Fisher Scientific). Elution was performed with a linear acetonitrile gradient (15-40\% in $115 \mathrm{~min}$ ) in $0.1 \%$ formic acid. Full-scan mass spectra were acquired in the Orbitrap MS over a mass range of $400-15,000 \mathrm{~m} / z$ with a resolution of 30,000 . A lock mass function was used to obtain high mass accuracy (Olsen et al., 2005). The top 10 most intense precursor ions were selected for collision-induced fragmentation in the linear ion trap at normalized collision energy of 35\%. Dynamic exclusion was employed within 90 s (Zhang et al., 2009) to prevent repetitive selection of peptides.

\section{IDENTIFICATION OF PROTEINS OBTAINED BY MASS SPECTROMETRY}

Identification of proteins was performed by the MASCOT search engine (version 2.4.1) (Matrix Science, London, UK) and Proteome Discoverer (version 1.4.0.288; Thermo Fischer Scientific) against a soybean peptide database ( 54,175 sequences) (Phytozome version 9.0, http://www.phytozome.net/soybean) (Schmutz et al., 2010). Parameters used in MASCOT searches were as follows: Carbamidomethylation of cysteine was set as a fixed modification, and oxidation of methionine was set as a variable modification. Trypsin was specified as the proteolytic enzyme and one missed cleavage was allowed. Peptide mass tolerance was set at $5 \mathrm{ppm}$, fragment mass tolerance was set at 0.8 $\mathrm{Da}$, and peptide charge was set at $+2,+3$, and +4 . An automatic decoy database search was also performed. MASCOT results were filtered with MASCOT percolator to improve accuracy and sensitivity in the peptide identification (Brosch et al., 2009). False discovery rates for peptide identification of all searches were less than $1.0 \%$. Peptides with a more than 13 peptide probability and percolator $q$-value 0.01 were used for protein identification. The MASCOT results generated msf files were used for SIEVE (version 2.0; Thermo Fisher Scientific) analysis.

To compare protein and peptide contents between different groups, extracted ion chromatograms (XIC) based comparison approach was used in the SIEVE software. For differential analysis of the relative abundance of peptides and proteins between the control and treatment groups, the commercial label-free quantification package SIEVE was used. The chromatographic peaks obtained from MS were aligned and the peptide peaks were detected as frames using the following settings: frame time width ( $5 \mathrm{~min}$ ); frame $\mathrm{m} / \mathrm{z}$ width $(10 \mathrm{ppm})$; produce frames on all parent ions subjected to MS/MS scan. The frames with MS/MS scan were matched to imported MASCOT results. The ratio of peptides between samples was determined from the variance-weighted average of the ratios in frames, which matched the peptides in the MS/MS spectrum. The ratios of peptides were further integrated to determine the ratio of the corresponding protein. In the differential analysis of protein abundance, total ion current was used for normalization. The requirement for the identification of a protein was a minimum of two matched peptides and two unique peptides. Significant changes in the abundance of proteins between the control and treated samples were analyzed $(p<0.05)$.

\section{ANALYSIS OF PROTEIN FUNCTION AND SUBCELLULAR LOCALIZATION}

Protein functions were categorized using MapMan bin code (Usadel et al., 2005). NetNGlyc (http://www.cbs.dtu.dk/ services/NetNGlyc/) (Gupta and Brunak, 2002) and N-Glycosite (http://www.hiv.lanl.gov/content/sequence/GLYCOSITE/glycosite. html) (Zhang et al., 2004) were used to predict the $\mathrm{N}$ glycosylation consensus sequence within the protein moiety of identified proteins. The identified proteins were predicted for the presence of $\mathrm{N}$-terminal ER targeting signal peptide with SignalP (http://www.cbs.dtu.dk/services/SignalP/), as this is essential for co-translational translocation of $\mathrm{N}$-glycosylation in the ER (Emanuelsson et al., 2007). Wolf PSORT (http://wolfpsort.org/) and TargetP (http://www.cbs.dtu.dk/services/TargetP/) were used to determine the predicted subcellular locations of the proteins.

\section{RNA EXTRACTION AND QUANTITATIVE REVERSE TRANSCRIPTION POLYMERASE CHAIN REACTION ANALYSIS}

A portion $(100 \mathrm{mg})$ of samples was ground into powder in liquid nitrogen with a sterilized mortar and pestle. Total RNA was extracted from the tissue powder using an RNeasy Plant Mini kit (Qiagen, Valencia, CA, USA). RNA was reverse-transcribed using an iScript cDNA Synthesis kit (Bio-Rad, Hercules, CA, USA) according to the manufacturer's instructions. qRT-PCR was performed in a $10 \mu \mathrm{L}$ reaction assay using SsoAdvanced SYBR Green Universal Supermix (Bio-Rad) and a MyiQ single-color real-time PCR detection system (Bio-Rad). The PCR conditions were as follows: $95^{\circ} \mathrm{C}$ for $210 \mathrm{~s}$, then 45 cycles of $95^{\circ} \mathrm{C}$ for $30 \mathrm{~s}$, 
$60^{\circ} \mathrm{C}$ for $30 \mathrm{~s}$, and $72^{\circ} \mathrm{C}$ for $30 \mathrm{~s}$. Gene expression was normalized using $18 \mathrm{~S}$ rRNA as an internal control. The primers were designed using the Primer3 web interface (http://frodo.wi.mit. edu). Specificity of primers used for the analysis was checked by the BLASTN search against the Phytozome-G.max database with the designed primers sequences as queries (Supplemental Table 1) and by melting curve analysis.

\section{STATISTICAL ANALYSIS}

The statistical significance of the results was evaluated with the Student's $t$-test. All calculations were performed by using Graphpad software (version 5.0). A $p<0.05$ was considered to be statistically significant.

\section{RESULTS AND DISCUSSION GLYCOPROTEIN PURIFICATION}

To characterize the glycoproteome of soybean roots submitted to a flooding stress, we have in the present work used a protocol previously described in our studies (Komatsu et al., 2013, 2014; Nanjo et al., 2013; Yin et al., 2014). In this protocol, soybean seeds were germinated under optimal control conditions for 2 days and growth is then continued either in control conditions or in flooding stress conditions. Proteomic analysis of the total protein extracts confirm the presence of flooding stress protein markers in the stressed roots, as alcohol dehydrogenase and HSP70 (Komatsu et al., 2013, 2014; Nanjo et al., 2013; Yin et al., 2014). Thereby this protocol was further used to characterize impact of the flooding stress on the glycoproteome of soybean roots. In order to understand the soybean response toward flooding stress, glycoproteomic analysis was performed according to the protocol depicted in Supplemental Figure 1. Proteins extracted from the soybean roots were separated by SDS-PAGE and crossreacted with ConA antibody (Supplemental Figure 2). The relative band intensities were calculated. The accumulation level of the extracted glycoproteins decreased slightly but significantly under flooding stress as compared to the controls (Figure 1). As the 4-day-old soybeans flooded for 2 days exhibited a significantly decreased accumulation of glycoproteins as compared to controls, this plant sample was further used for glycoproteomic analysis, which was performed using the enriched glycoprotein fraction, as described under materials and methods. The extent of glycoproteins present in the total protein extracts and in the glycoprotein-enriched extracts was compared by Western blotting using ConA antibody (Supplemental Figure 2). It is clear that the intensities of glycoprotein bands were higher in the glycoproteinenriched protein extracts than in corresponding total protein extracts, testifying the efficiency of the presently used protocol. ConA lectin has broad specificity for high mannose, hybrid, and biantennary complex-type N-glycan (Madera et al., 2008). The present results indicated that glycoproteins were selectively enriched using the ConA lectin resin (Supplemental Figure 2). However, to reduce the false discovery rate for the glycoprotein enrichment, specific glycan-binding lectin could be used. Indeed, in mammals, the combination of lectins enriched different protein subsets (Lee et al., 2010). Therefore, in future work, specific glycan-binding lectin could be used to improve the glycoprotein in soybean roots.

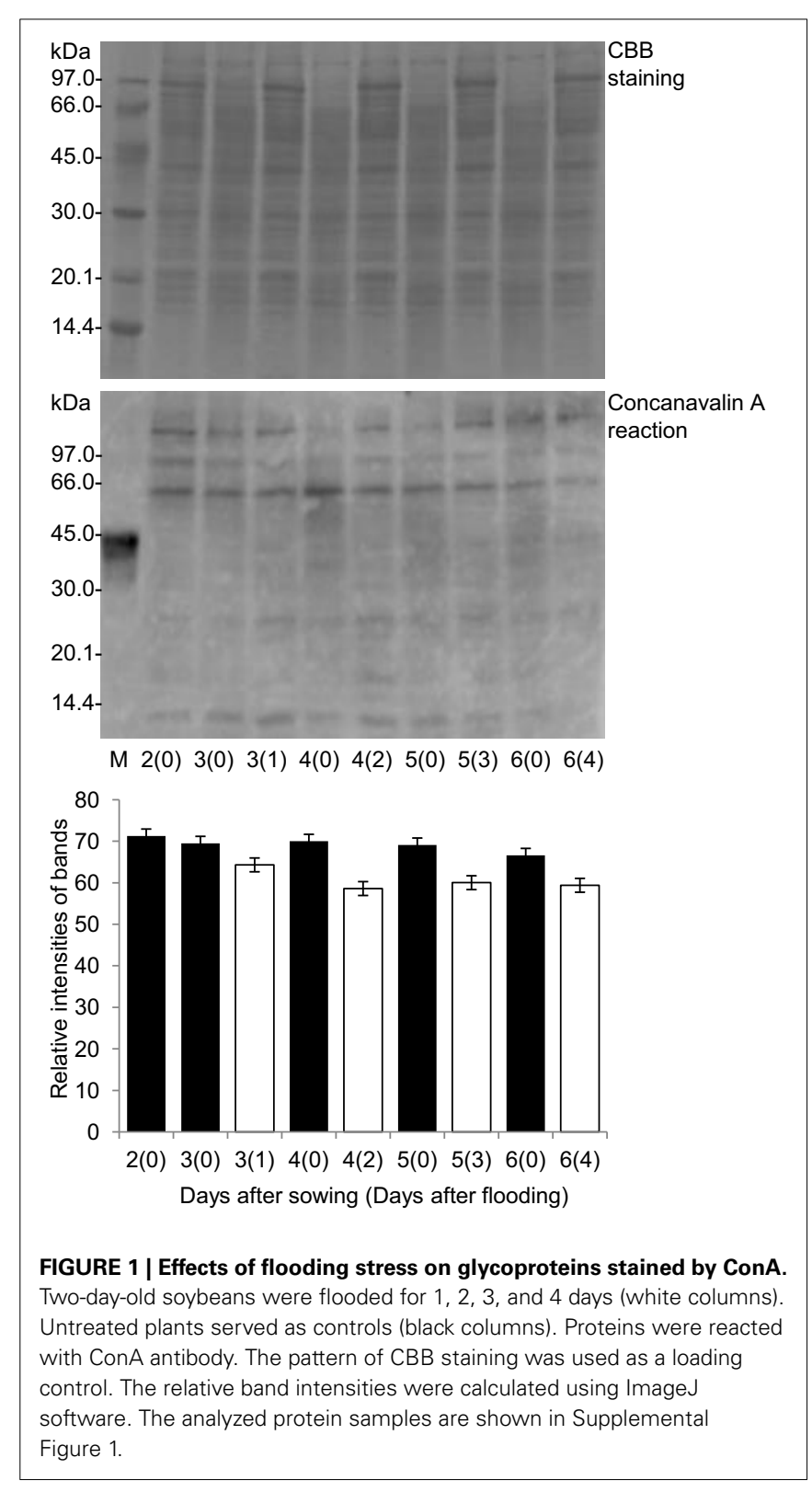

\section{IDENTIFICATION OF ENRICHED GLYCOPROTEINS USING A GEL-FREE PROTEOMICS TECHNIOUE}

To understand role of the glycoproteins whose accumulation levels changed under flooding stress in soybean roots, glycoproteomics was performed as described in Supplemental Figure 1. In the differential analysis of the glycoproteins, the accumulation levels of 149 proteins were significantly changed in 4-day-old soybean roots compared to the 2-day-old roots under control conditions (Supplemental Table 2). These identified proteins were analyzed for the presence of $\mathrm{N}$-glycosylation sites within the protein moiety using NetNGlyc software, and 111 proteins were found to contain the putative N-glycosylation site. Out of these 111 proteins, the accumulation level of 51 glycoproteins increased and that of 60 glycoproteins were decreased significantly (Supplemental Table 2). SIEVE software was used 


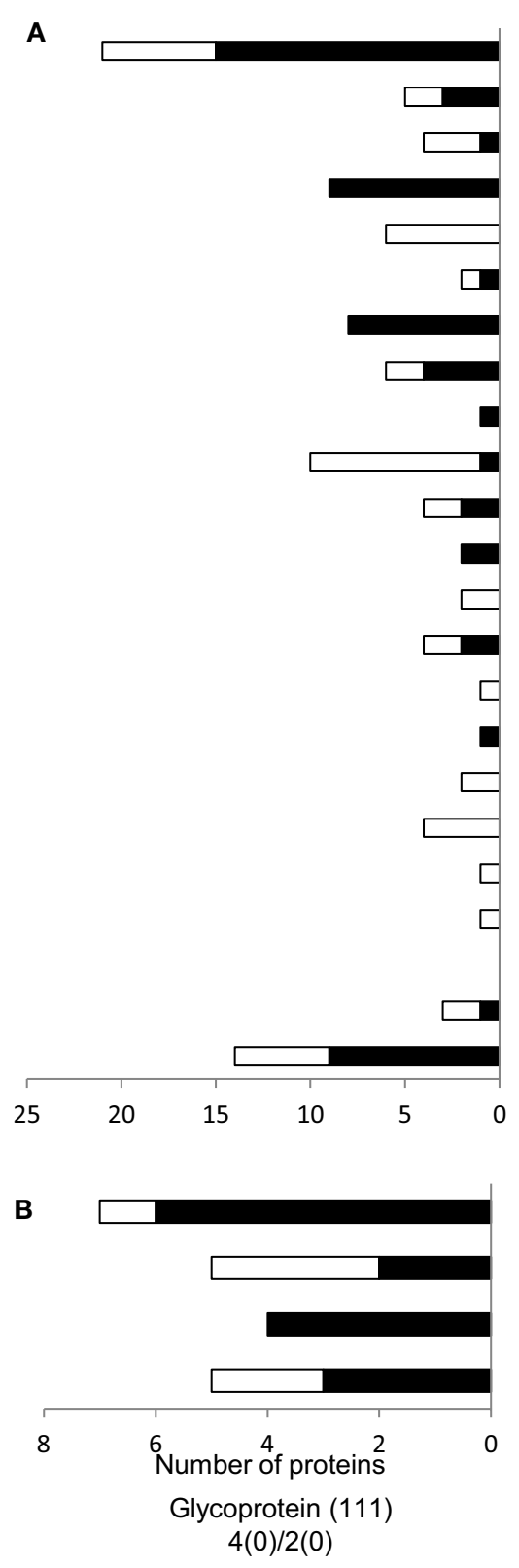

FIGURE 2 | Functional categorization of the identified glycoproteins. (A) MapMan bin code was used to predict the functional categorization of the identified glycoproteins. The X-axis indicates the number of identified proteins. Filled bars and open bars indicate increased and decreased glycoproteins in soybean roots under flooding stress, respectively. (B) Categorization of the proteins related to protein synthesis, degradation, and post-translational

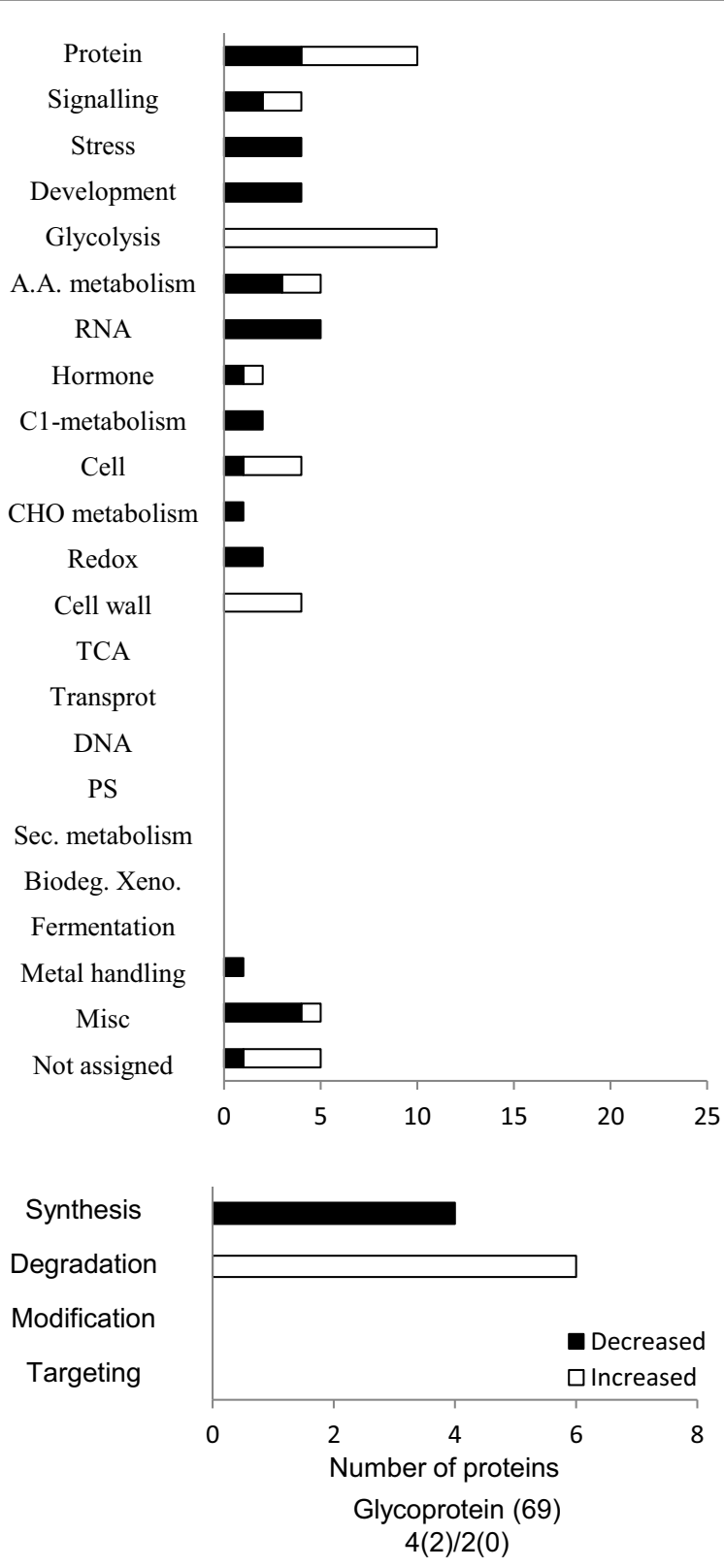

modifications. Abbreviations: Protein, Protein synthesis/degradation/ post-translational modification/targeting; A.A. metabolism, amino acid metabolism; RNA, RNA processing/transcription/binding; C1-metabolism, Carbon 1-metabolism; CHO-metabolism, carbohydrate metabolism; DNA, DNA synthesis; PS, photosynthesis; Sec. metabolism, secondary metabolism; Misc., miscellaneous. for the comparison of relative abundance of proteins under control unstressed conditions from three biological replicates (Supplemental Table 3). From this analysis, 87 proteins differentially accumulated following 2 days of flooding stress, with 41 and 46 proteins showing increased and decreased abundance, respectively. From these, 69 proteins contained the putative $\mathrm{N}$-glycosylation site with 34 and 35 proteins exhibiting increased and decreased accumulation levels, respectively (Supplemental
Table 4). Peptide sequences and the SIEVE data for three biological replicates were also listed (Supplemental Table 5) highlighting the changes in protein abundance occurring under flooding conditions. Out of the glycoproteins exhibiting changes in accumulation levels under 2 days of flooding stress, concanavalin A like lectin kinase protein (Glyma09g27700.1), polygalacturonase inhibiting protein 1 (Glyma05g25370.1), and SNF1 related protein kinase regulatory subunit gamma 1 (Glyma17g13880.2) 
accumulated more than 10-fold under flooding stress compared to control conditions, while peroxidase superfamily protein (Glyma12g32160.1), evolutionarily conserved C terminal region (Glyma08g13130.1), and nucleolin (Glyma11g10790.1) showed decreased abundance under the flooding stress conditions.

Among the identified glycoproteins, most of them have already been reported in response to flooding stress in soybean. This was, for example, the case for the polygalacturonase inhibiting proteins, peroxidase, and glyceraldehyde 3 phosphate dehydrogenase (Komatsu et al., 2012; Nanjo et al., 2013). In other species, the homologs of these proteins were shown to display relatively similar behavior under stress conditions. For example, glyceraldehyde 3 phosphate dehydrogenase displayed increased accumulation in Solanum tuberosum (Laxalt et al., 1996) and in maize (Chalivendra and Martin, 2003). Also, in rice glycosyl hydrolases were reported to be upregulated under submergence stress conditions (Opassiri et al., 2007). While clathrin heavy chain homologs have been shown to accumulate under salt stress (McLoughlin et al., 2013).

Polygalacturonase inhibiting proteins have been reported to be involved in impairing seed germination by inhibiting pectin degradation, which in turn is regulated by the transcription factor AB15 (Kanai et al., 2010). Under water deficit conditions, abscisic acid accumulation is greater in soybean seedling root tips as compared to other tissues. Komatsu et al. (2013) reported that abscisic acid, through the control of energy conservation via the glycolytic system, enhances the flooding tolerance of soybean root. Ahsan et al. (2005) reported that polygalacturonase is upregulated in response to various abiotic stresses like cold and salinity. In soybean, two polygalacturonase inhibiting protein members have been reported to be upregulated in response to pathogenic infection (Ovidio et al., 2004), one of which was found to show increased accumulation under drought and flooding stress in Lathyrus sativus (Tamburino et al., 2012). In agreement with this, Komatsu et al. (2009) reported an increase of these polygalacturonase inhibiting proteins under flooding stress in soybean roots. In the present study, we observed increased accumulation of polygalacturonas inhibiting proteins under flooding stress.

In this study, the accumulation level of glyceraldehyde 3 phosphate dehydrogenase increased under flooding stress (Supplemental Table 4). Previous reports have indicated that under low oxygen conditions, glycolysis and carbohydrate metabolism related proteins are activated, which might be related to the response under energy deprived conditions (Huang and Johnson, 1995). In soybean root, the glyceraldehyde 3 phosphate dehydrogenase protein has been reported to show increased accumulation under flooding stress (Nanjo et al., 2010). Altogether, these results lend further support for the role of the presently characterized glycoproteins in flooding stress response and suggest that plants remodel their glycoproteome to cope with unfavorable environmental conditions.

\section{FUNCTIONAL ANALYSIS AND SUBCELLULAR LOCALIZATION OF GLYCOPROTEINS}

To get a better understanding of the biological processes that were altered by flooding stress, the identified glycoproteins were functionally classified. Functional categorization was performed using MapMan bin code (Usadel et al., 2005). Functional categorization showed that the 69 flooding stress responsive glycoproteins are involved in protein synthesis/degradation (19\%), glycolysis (15\%), cell organization (9\%), development $(8 \%)$, and RNA (7\%) (Figure 2A). Proteins related to protein degradation showed significant increased accumulation under flooding stress (Figure 2B). Quantitative proteomics analysis indicated that glycoproteins related to protein degradation, cell wall, and glycolysis display increased abundance under flooding stress, while stress related proteins showed decreased abundance, which is consistent with previous findings (Nanjo et al., 2010, 2011). Among the proteins involved in protein synthesis and degradation, more proteins involved in protein degradation were increased under flooding stress. Under flooding stress, Rorippa amphibia shows upregulated genes involved in glycolysis and fermentation that indicate a higher demand for energy production under stress

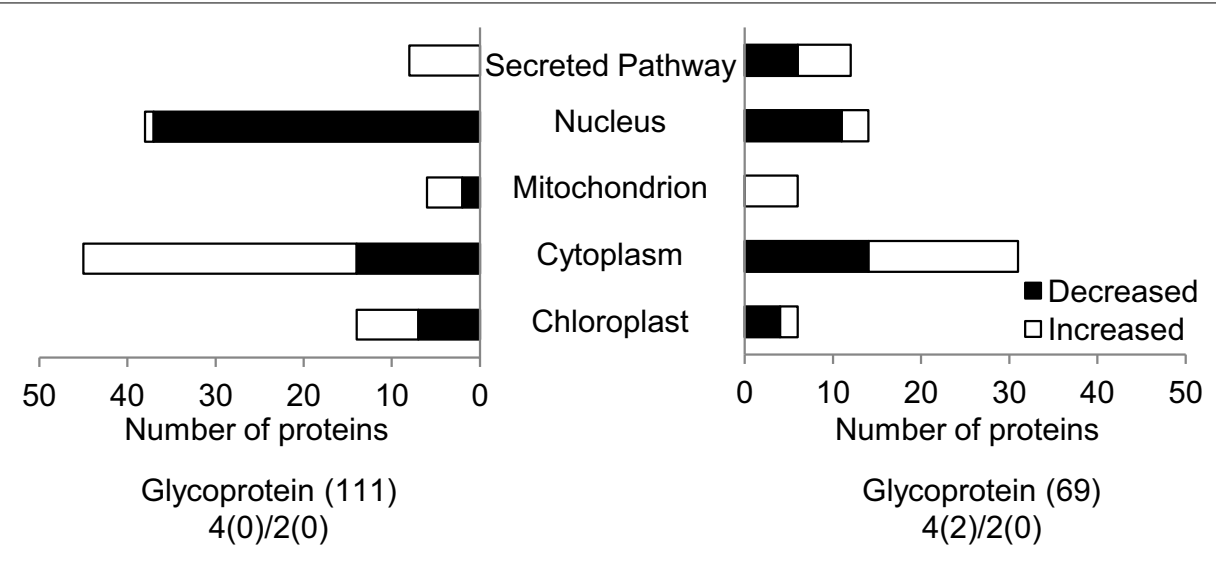

FIGURE 3 | Subcellular localization of the identified glycoproteins. Wolf PSORT and TargetP were used to predict the subcellular localization of the identified glycoproteins. The $\mathrm{X}$-axis indicates the number of identified proteins. Filled bars and open bars indicate glycoproteins whose accumulation levels increased and decreased in soybean roots under flooding stress, respectively. 


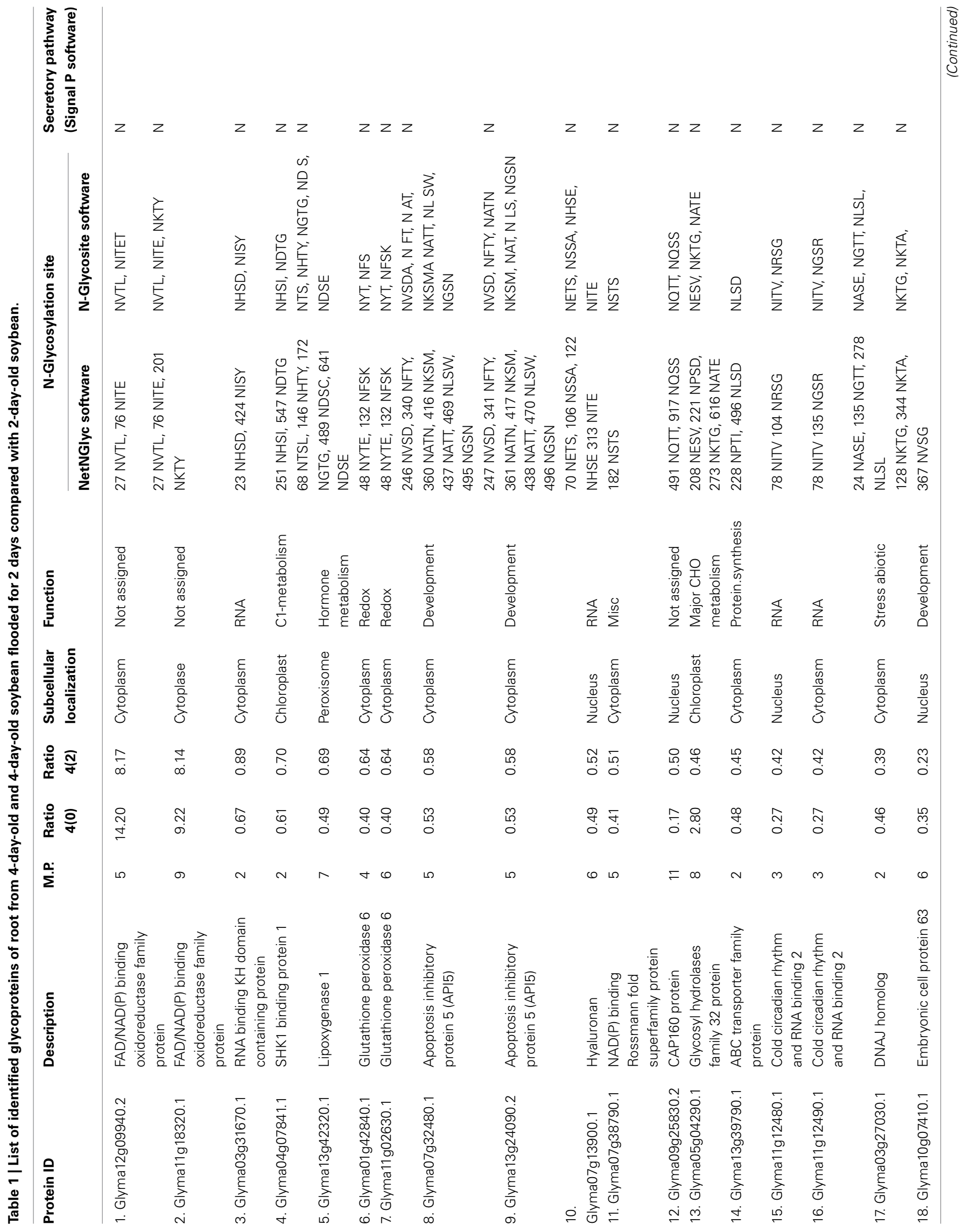




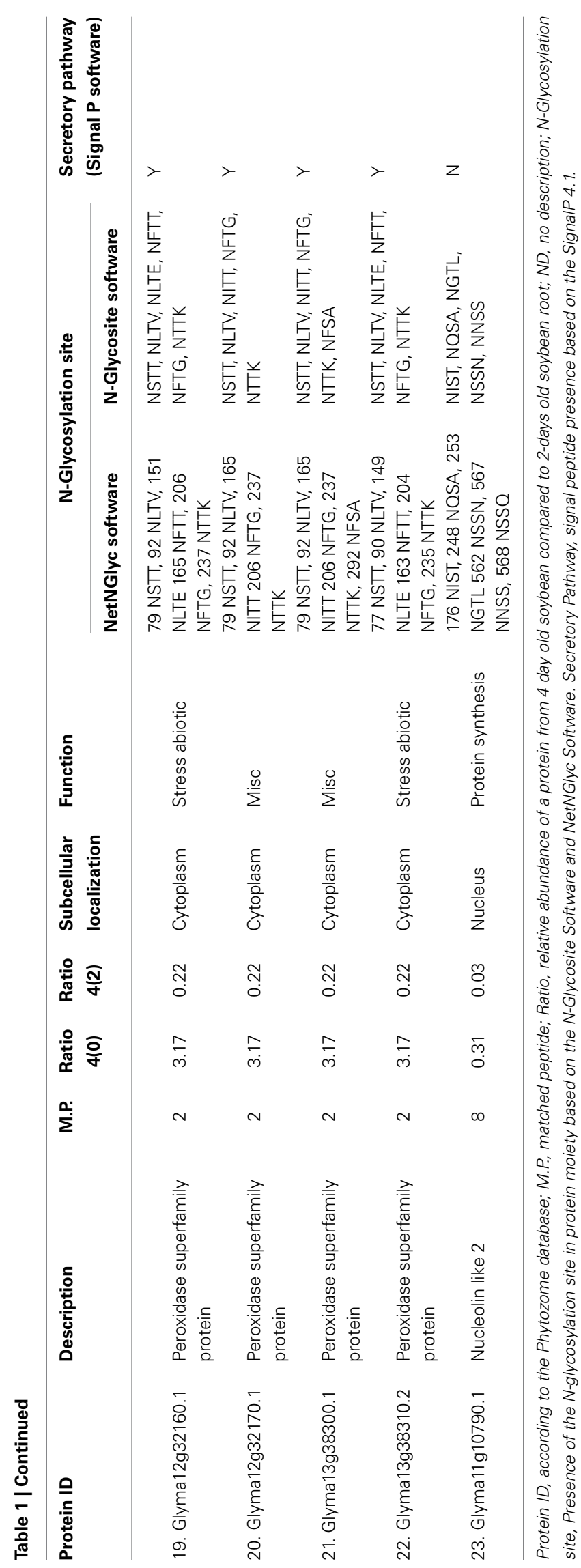

conditions (Akman et al., 2014). In soybean seedlings, an increase in glycolysis related proteins has been reported under flooding stress (Nanjo et al., 2010, 2011). These results suggest that changes in glycolysis related proteins contribute to energy production, and that this could be an acclimation response of soybean roots toward flooding stress.

To further decipher the role of the presently identified flooding responsive glycoproteins, a subcellular localization analysis of these identified glycoproteins was performed using Wolf PSORT (Horton et al., 2007) and TargetP (Emanuelsson et al., 2007) (Figure 3). Out of the presently identified 69 glycoproteins, 31 were predicted to be localized in the cytoplasm (45\%), while 14 and 12 glycoproteins were localized in the nucleus $(20 \%)$ and secretory pathway $(17 \%)$, respectively (Figure 3). Proteins related to the secretory pathway showed significant decreased abundance under flooding stress. Secretory pathway related proteins like peroxidase superfamily proteins and glycosyl hydrolases displayed decreased accumulation levels in soybean roots under flooding stress (Figure 4, Table 1).

Plant peroxidases are secreted glycoproteins involved in numerous mechanisms, like cell elongation, cell wall construction, and defense against pathogens (Kukavica et al., 2012). Peroxidase super family proteins are induced by drought in wild watermelons (Yoshimura et al., 2008) and maize roots (Degenhardt and Gimmler, 2000), suggesting enhanced lignin production. Peroxidases have been reported to be in lower abundance under flooding stress (Shi et al., 2008; Komatsu et al., 2010, 2012). In soybean root, peroxidase genes have been reported to be downregulated under flooding stress (Nishizawa et al., 2013). Under flooding stress, the soybean seedlings show reduced growth (Hashiguchi et al., 2009). This growth inhibition functions to conserve energy under stress conditions and promotes survival by anaerobic respiration (Nanjo et al., 2011). The observed decreased abundance of peroxidase superfamily proteins under flooding stress (Table 1, Supplemental Table 6), suggesting decreased lignin synthesis and ultimately a reduction in cell wall formation. In agreement, a proteomic analysis of soybean root cell wall proteins disclosed the suppression of the lignification process under flooding stress conditions (Komatsu et al., 2010). This could be a plant strategy to conserve energy under stress conditions.

Glycosyl hydrolase proteins are involved in the biosynthesis of glycans and plant defense. Glycosyl hydrolases family 32 proteins have been reported to be of the acid invertase type that functions as cell wall invertases (Lammens et al., 2009). In the cell, glycosyl hydrolases are responsible for the cleavage of glycosidic linkages and play a role in glycan processing (Trincone and Giordano, 2006). These proteins catalyze the hydrolysis of glycosidic bonds between sugars and other moieties (Henrissat and Davies, 1997). In rice, glycosyl hydrolases are induced under stress conditions (Opassiri et al., 2007). In this study, glycosyl hydrolases showed decreased abundance in soybean roots submitted to flooding stress (Table 1). These results suggest that flooding stress might cause a reduction in glycan synthesis that ultimately leads to decreased glycoprotein synthesis in soybean roots. 


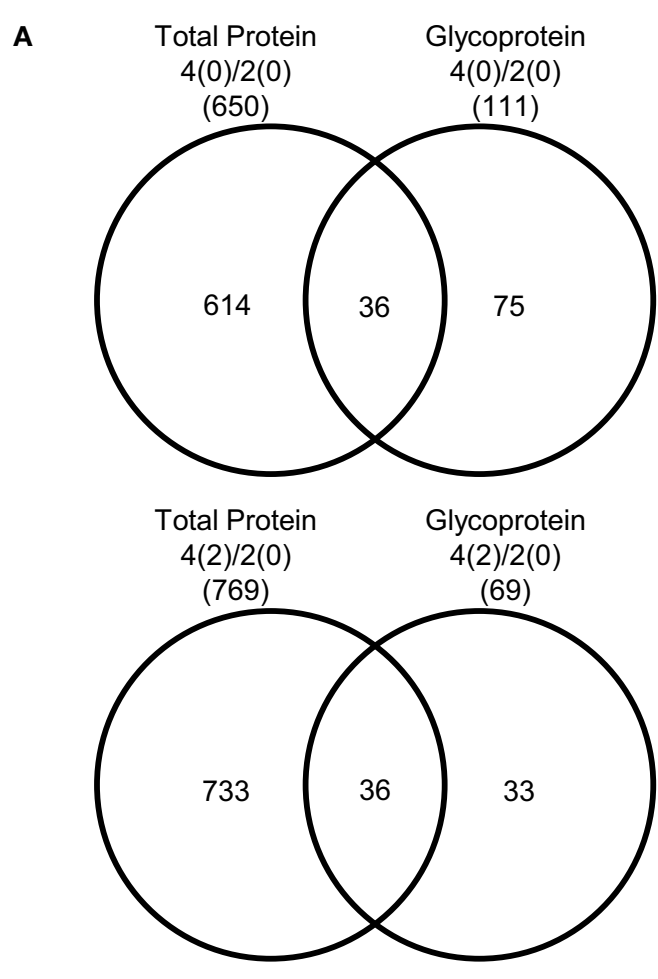

B

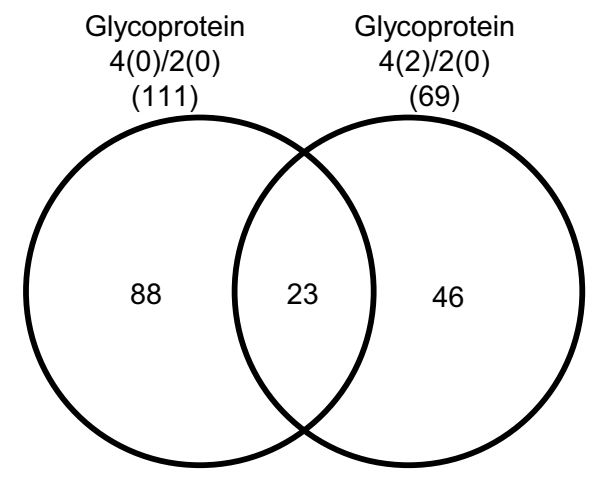

FIGURE 4 | Comparison of the proteins identified from soybean root. (A) Total proteins identified from 4-day-old soybean roots compared to the glycoproteins in the control. Total proteins identified from 2-day-old soybean roots flooded for 2 days were compared to the glycoproteins. (B) Glycoproteins identified from 4-day-old flooded for 2 days soybean roots compared to glycoproteins identified from 4-days-old soybean roots.

\section{EFFECT OF FLOODING STRESS ON N-GLYCOSYLATION AND ER-RELATED GENES}

To understand the effect of flooding stress on the process of N-glycosylation, the mRNA expression levels of four Nglycosylation-related genes (Figure 5) and three ER-related genes (Figure 6) were analyzed using qRT-PCR. Among $\mathrm{N}$-glycosylation-related genes, glucosaminephosphotransferase (Glyma02g34640.1), alpha-1, 2 glucosyltransferase (Glyma07g15720.1), STT3 subunit of oligosaccharyltransferase (Glyma01g01270.1), and mannosyl-oligosaccharide glucosidase
(Glyma05g27890.1) were analyzed. Among ER-related genes, protein disulfide isomerase (Glyma01g25050.1), luminal binding protein 5 (Glyma08g02940.1), and calreticulin (Glyma20g23080.1) were analyzed. In these experiments, 2day-old soybeans were flooded for 1 and 2 days. Total RNA was extracted and analyzed. Untreated plants served as controls.

The mRNA expression levels of glucosaminephosphotransferase, an enzyme that is involved in starting the process of $\mathrm{N}$-glycan synthesis at the cytoplasmic face of the ER (Koizumi et al., 1999), alpha-1, 2 glucosyltransferase, and STT3 subunit of oligosaccharyltransferase were downregulated under 1 day of flooding stress (Figure 5). Mannosyl-oligosaccharide glucosidase, which is involved in N-glycan trimming (Gillmor et al., 2002), was downregulated under flooding stress for 1 day and upregulated under flooding stress for 2 days (Figure 5). These results indicated that the process of N-glycosylation and ultimately glycoprotein synthesis was significantly downregulated under 1-day flooding stress. The mRNA expression level of protein disulfide isomerase, was upregulated under flooding stress conducted for 2 days (Figure 6). Luminal binding protein 5, which interacts with polypeptide folding intermediates (Morris et al., 1997) and calreticulin, which is responsible for the folding of newly synthesized polypeptide chains and glycoproteins (Michalak et al., 2002), were downregulated under 1 day of flooding stress. Protein disulfide isomerase inserts disulfides into proteins and provides mechanism to correct errors in disulfide pairing (Gilbert, 1997). In pea roots, protein disulfide isomerase was detected in relatively high abundance under stress conditions. The observed downregulation of luminal binding protein and calreticulin under flooding stress indicates that the protein folding process in the ER had been disrupted because these are important for protein folding. These results indicated that protein folding was disrupted in the ER.

Alpha-1, 2 glucosyltransferase, which is involved in the process of glycan extension (Farid et al., 2011), was downregulated under flooding stress. Farid et al. (2011) reported that alpha-1, 2 glucosyltransferase in Arabidopsis is required for lipid-linked oligosaccharide biosynthesis and the abiotic stress response. Furthermore, inactivation of alpha-1, 2 glucosyltransferase results in the activation of the unfolded protein response and increased sensitivity to salt stress. Burda and Aebi (1998) reported that mutants lacking this gene experience decreased glycosylation in Saccharomyces cerevisiae. These results suggest that downregulation of the mRNA expression level of alpha-1, 2 glucosyltransferase in soybean root under flooding stress leads to decreased glycosylation.

The mRNA expression level of the STT3 subunit of oligosaccharyltransferase, which is involved in glycan transfer to asparagine residues in target proteins (Koiwa et al., 2003), was downregulated in soybean root under flooding stress (Figure 5). The oligosaccharyltransferase complex governs the central step of N-glycosylation, which transfers the preassembled oligosaccharide to the protein in the ER (Mohorko et al., 2011). In Arabidopsis, the STT3 subunit has been reported to control the plant response toward salt/osmotic stress (Koiwa et al., 2003). STT3 subunit deficiency results in protein underglycosylation defects that disturb the biogenesis of heavily glycosylated proteins and ultimately plant innate immunity (Nekrasov et al., 2009). 

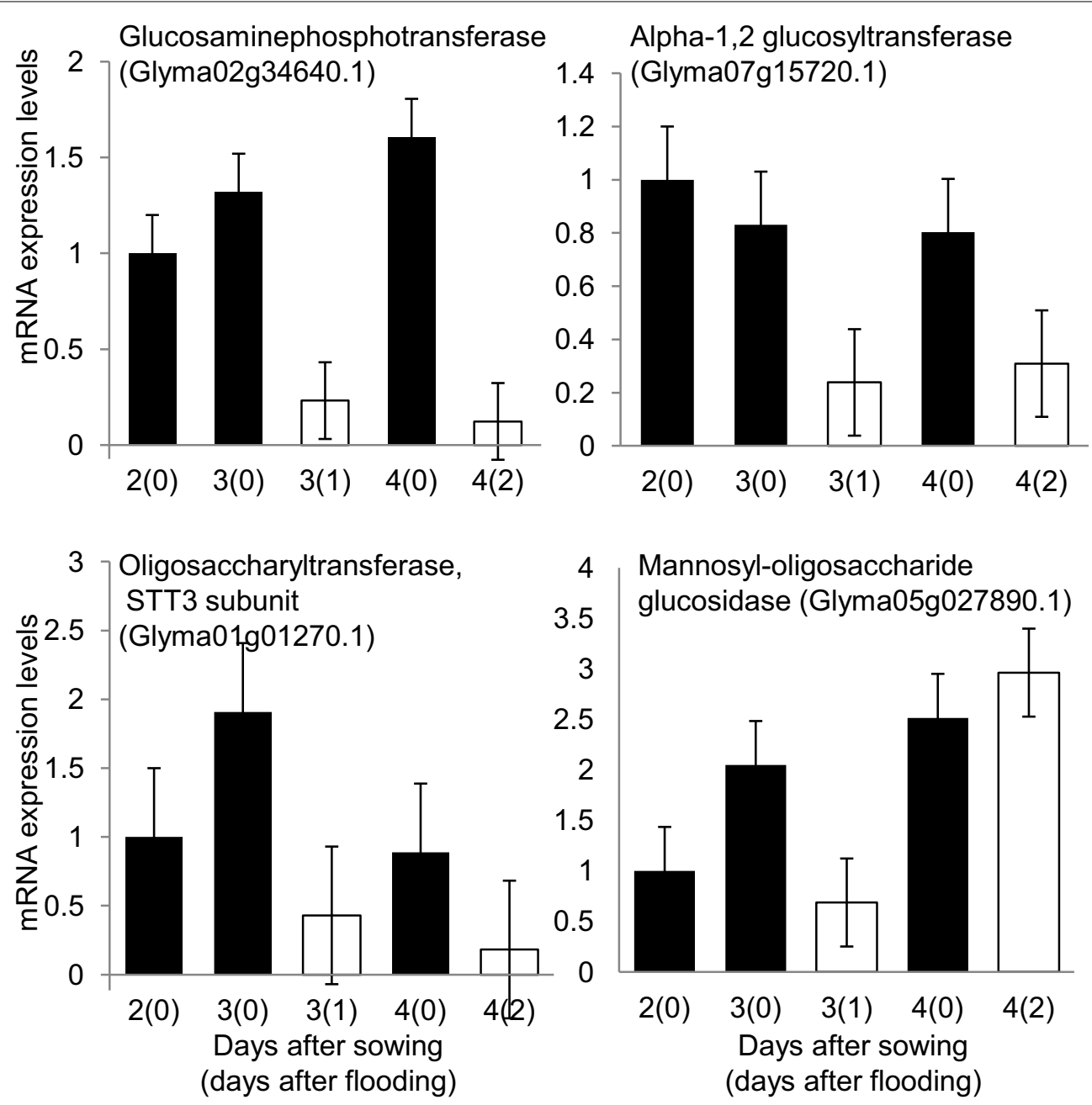

FIGURE 5 | Effects of flooding stress on mRNA expression levels of $\mathbf{N}$-glycosylation related genes. Two-day-old soybeans were treated with flooding for 1 and 2 days (white column). Untreated plants served as a control (black column). RNA extracted from roots of soybean was analyzed by GRT-PCR with specific primers for N-glycosylation genes (Supplemental Table 1; Supplemental Figure 1 for the analyzed samples). mRNA expression levels indicate relative
mRNA abundance normalized against 18S rRNA abundance. The data shows mean \pm SE values from three independent biological replicates. Among N-glycosylation related genes, glucosaminephosphotransferase (Glyma02g34640.1), alpha-1, 2 glucosyltransferase (Glyma07g15720.1), oligosaccharyltransferase, STT3 subunit (Glyma01g01270.1), and mannosyl-oligosaccharide glucosidase (Glyma05g27890.1) were selected.
In this way, plants could modify their system to cope with stress conditions. The downregulation of the STT3 subunit of oligosaccharyltransferase might an imporatant part of the response of plant toward flooding stress. Soybean plants under flooding stress might experience underglycosylation that leads to the decreased glycoprotein levels. The downregulation of the genes involved in protein glycosylation was clearly noticed at the proteomic level (Figure 5).

The gene encoding protein disulfide isomerase, which is involved in the formation of disulfide bonds in nascent polypeptide chains (Freedman et al., 1994), was upregulated in soybean roots under flooding stress (Figure 6). Protein disulfide isomerase family proteins are involved in polypeptide folding and the formation of the disulfide bonds in the ER (Freedman et al., 1994). Protein disulfide isomerase is sorted to the ER to behave as a chaperone for reconstructing misfolded proteins in this compartment (Wang et al., 2012), and is involved in the quality control of storage proteins (Kamauchi et al., 2008). Stressful conditions result in the accumulation of misfolded proteins in the ER (Liu and Howell, 2010). These results suggest that under flooding stress conditions, the upregulation of protein disulfide isomerase might help to reduce misfolded proteins in the ER. This upregulation could be a remodeling strategy to reconstruct misfolded proteins and specifically glycoproteins in stressed plants.

\section{CONCLUDING REMARKS}

Gel-free glycoproteomics proved useful to uncover the mechanisms that are involved in early stages of soybean response against flooding stress. A total of 69 glycoproteins from soybean roots were found to display significant changes in abundance 

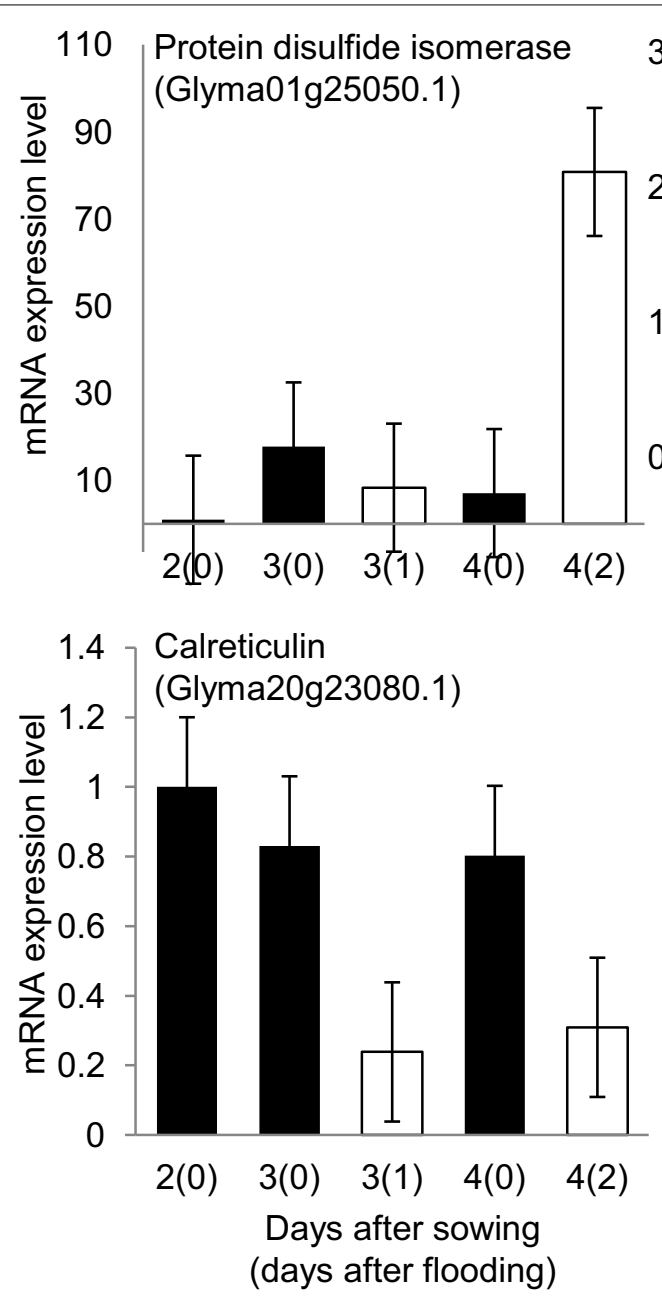

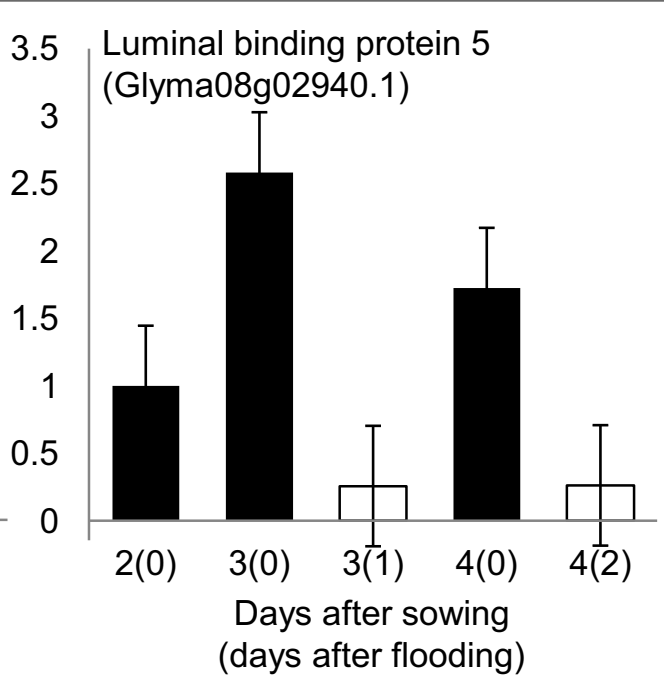

expression levels indicate relative mRNA abundance normalized against $18 \mathrm{~S}$ rRNA abundance. The data shows mean \pm SE values from three independent biological replicates. Among ER related genes, protein disulfide isomerase (Glyma01g25050.1), luminal binding protein 5 (Glyma08g02940.1), and calreticulin (Glyma20g23080.1) were selected. under 2 days of flooding stress. Functional categorization of these identified glycoproteins indicated that the majority were related to glycolysis and protein degradation. Subcellular prediction of these identified glycoproteins indicated their localization to the cytoplasm, nucleus, and secretory pathways. Proteins involved in energy metabolism such as glyceraldehydes 3 phosphate dehydrogenase were found to have increased accumulation under flooding stress. mRNA expression levels of genes involved in the N-glycosylation pathway indicated a downregulation at every step of that pathway. From the present results, and as previously observed (Baerenfaller et al., 2008; Piques et al., 2009; Schwanhäusser et al., 2011; Galland et al., 2014), it appears that mRNA and protein accumulation profiles differ. We suggest that this behavior originates from the various check points in gene expression and also from different extents of protein and mRNA stability levels. Altogether, our present results document for the first time that a flooding stress entails a large modification in the glycoproteome of soybean roots, which may provide new avenues for the selection of novel soybean varieties more resistant to this stress compromising crop yield.

\section{ACCESSION CODE}

The mass spectrometry proteomics data have been deposited to the ProteomeXchange Consortium (http://proteomecentral. proteomexchange.org) via the PRIDE partner repository (Vizcaíno et al., 2013) with the data set identifier and doi PXD001350.

\section{ACKNOWLEDGMENTS}

The authors thank Dr. Yohei Nanjo, Dr. Keito Nishizawa, Ms. MyeongWon Oh, and Mr. Xiaojian Yin at the National Institute of Crop Science for their valuable discussions.

\section{SUPPLEMENTARY MATERIAL}

The Supplementary Material for this article can be found online at: http://www.frontiersin.org/journal/10.3389/fpls.2014. 00627/abstract 


\section{REFERENCES}

Abeijon, C., and Hirscnberg, C. B. (1992). Topography of glycosylation reactions in the endoplasmic reticulum. Trends Biochem. Sci. 17, 32-36. doi: 10.1016/09680004(92)90424-8

Ahsan, N., Yoon, H. S., and Jo, J. (2005). Molecular cloning of a BcPGIP cDNA from Brassica campestris and its expression to several stresses. Plant Sci. 169, 1081-1089. doi: 10.1016/j.plantsci.2005.07.006

Akman, M., Bhikharie, A., Mustroph, A., and Sasidharan, R. (2014). Extreme flooding tolerance in Rorippa. Plant Signal Behav. 13:9. doi: 10.4161/psb.27847

Baerenfaller, K., Grossmann, J., Grobei, M. A., Hull, R., Hirsch-Hoffmann, M., Yalovsky, S., et al. (2008). Genome-scale proteomics reveals Arabidopsis thaliana gene models and proteome dynamics. Science 16, 938-941. doi: 10.1126/science. 1157956

Beck, E. H., Fettig, S., Knake, C., Hartig, K., and Bhattarai, T. (2007). Specific and unspecific responses of plants to cold and drought stress. J. Biosci. 32, 501-510. doi: 10.1007/s12038-007-0049-5

Beck, E. H., Heim, R., and Hansen, J. (2004). Plant resistance to cold stress: mechanisms and environmental signals triggering frost hardening and dehardening. J. Biosci. 29, 449-459. doi: 10.1007/BF02712118

Bita, C. E., and Greats, T. (2013). Plant tolerance to high temperature in a changing environment: scientific fundamentals and production of heat stress-tolerant crops. Front. Plant Sci. 4:273. doi: 10.3389/fpls.2013.00273

Bradford, M. M. (1976). A rapid and sensitive method for the quantitation of microgram quantities of protein utilizing the principle of protein-dye binding. Anal. Biochem. 72, 248-254. doi: 10.1016/0003-2697(76)90527-3

Brosch, M., Yu, L., Hubbard, T., and Choudhary, J. (2009). Accurate and sensitive peptide identification with MASCOT percolator. J. Proteome Res. 8, 3176-3181. doi: $10.1021 /$ pr800982s

Burda, P., and Aebi, M. (1998). The ALG10 locus of Saccharomyces cerevisiae encodes the $\alpha-1,2$ glucosyltransferase of the endoplasmic reticulum: the terminal glucose of the lipid-linked oligosaccharide is required for efficient N-linked glycosylation. Glycobiology 8, 455-462. doi: 10.1093/glycob/ 8.5.455

Catala, C., Howe, K. J., Hucko, S., Rose, J. K. C., and Thannhauser, T. W. (2011). Towards characterization of the glycoproteome of tomato (Solanum Lycopersicum) fruit using Concanavalin A affinity chromatography and LC-MALDI-MS/MS analysis. Proteomics 11, 1530-1544. doi: $10.1002 /$ pmic. 201000424

Chalivendra, C. S., and Martin, M. S. (2003). Molecular and cellular adaptations of maiz to flooding stress. Ann. Bot. 90, 119-127. doi: 10.1093/aob/mcf210

Coe, H., and Michalak, M. (2010). ERp57, a multifunctional endoplasmic reticulum resident oxidoreductase. Int. J. Biochem. Cell Biol. 42, 796-799. doi: 10.1016/j.biocel.2010.01.009

Degenhardt, B., and Gimmler, H. (2000). Cell wall adaptations to multiple environmental stresses in maize roots. J. Exp. Bot. 51, 595-603. doi: 10.1093/jexbot/51.344.595

Eigenbrod, F., Gonzalez, P., Dash, J., and Steyl, I. (2014). Vulnerability of ecosystems to climate change moderated by habitat intactness. Glob. Chang Biol. doi: 10.1111/gcb.12669. [Epub ahead of print].

Emanuelsson, O., Brunak, S., Heijne, G. V., and Nielsen, H. (2007). Locating proteins in the cell using TargetP, SignalP, and related tools. Nat. Protoc. 2, 953-971. doi: 10.1038/nprot.2007.131

Farid, A., Pabst, M., Schobere, J., Altmann, F., Glossl, J., and Strasser, R. (2011). Arabidopsis thaliana alpha 1,2-glucosyltransferase (ALG10) is required for efficient N-glycosylation and leaf growth. Plant J. 68, 314-325. doi: 10.1111/j.1365313X.2011.04688.x

Freedman, R. B., Hirst, T. R., and Tuite, M. F. (1994). Protein disulphide isomerise: building bridges in protein folding. Trends Biochem. Sci. 19, 331-336. doi: 10.1016/0968-0004(94)90072-8

Galland, M., Huguet, R., Arc, E., Cueff, G., Job, D., and Rajjou, L. (2014). Dynamic proteomics emphasizes the importance of selective mRNA translation and protein turnover during Arabidopsis seed germination. Mol. Cell Proteomics 13, 252-268. doi: 10.1074/mcp.M113.032227

Gilbert, H. F. (1997). Protein disulfide isomerase and assisted protein folding. J. Biol. Chem. 272, 29399-29402. doi: 10.1074/jbc.272.47.29399

Gillmor, C. S., Poindexter, P., Lorieau, J., Palcic, M. M., and Somerville, C. (2002). Alpha-glucosidase I is required for cellulose biosynthesis and morphogenesis in Arabidopsis. J. Cell Biol. 10, 1003-1013. doi: 10.1083/jcb.200111093
Githiri, S. M., Watanabe, S., Harada, K., and Takahashi, R. (2006). QTL analysis of flooding tolerance in soybean at an early vegetative growth stage. Plant Breed. 125, 613-618. doi: 10.1111/j.1439-0523.2006.01291.x

Gupta, R., and Brunak, S. (2002). Prediction of glycosylation across the human proteome and the correlation to protein function. Pac. Symp. Biocomput. 7, 310-322.

Hao, X. Y., Han, X., Ju, H., and Lin, E. D. (2010). Impact of climatic change on soybean production: a review. Ying Yong Sheng Tai Xue Bao. 21, 2697-2706.

Hashiguchi, A., Sakata, K., and Komatsu, S. (2009). Proteome analysis of early stage soybean seedlings under flooding stress. J. Proteome Res. 8, 2058-2069. doi: $10.1021 / \mathrm{pr} 801051 \mathrm{~m}$

Henrissat, B., and Davies, G. (1997).Structural and sequence-based classification of glycoside hydrolases. Curr. Opin. Struct. Biol. 7, 637-644. doi: 10.1016/S0959440X(97)80072-3

Horton, P., Park, K. J., Obayashi, T., Fujita, N., Harada, H., Adams-Collier, C. J., et al. (2007). WoLF PSORT: protein localization predictor. Nucleic Acids Res. 35, W585-W587. doi: 10.1093/nar/gkm259

Hou, F. F., and Thseng, F. S. (1991). Studies on the flooding tolerance of soybean seed: varietal differences. Euphytica 57, 169-173. doi: 10.1007/BF00023075

Huang, B., and Johnson, J. W. (1995). Root respiration and carbohydrate status of two wheat genotypes in response to hypoxia. Ann. Bot. 75, 427-432. doi: 10.1006/anbo.1995.1041

Kamauchi, S., Wadahama, H., Iwasaki, K., Nakamoto, Y., Nishizawa, K., Ishimoto, M., et al. (2008). Molecular cloning and characterization of two soybean protein disulfide isomerases as molecular chaperones for seed storage proteins. FEBS J. 275, 2644-2658. doi: 10.1111/j.1742-4658.2008.06412.x

Kanai, M., Nishimura, M., and Hayashi, M. (2010). A peroxisomal ABC transporter promotes seed germination by inducing pectin degradation under the control of AB15. Plant J. 62, 936-947. doi: 10.1111/j.1365-313X.2010.04205.x

Koiwa, H., Li, F., McCully, M. G., Mendoza, I., Koizumi, N., Manabe, Y., et al. (2003). The STT3a subunit isoform of Arabidopsis oligosaccharyltransferase controls adaptive responses to salt/osmotic stress. Plant Cell 15, 2273-2284. doi: 10.1105/tpc.013862

Koizumi, N., Ujino, T., Sano, H., and Chrispeels, M. J. (1999). Overexpression of a gene that encodes the first enzyme in the biosynthesis of asparagineslinked glycans makes plants resistant to tunicamycin and obviates the tunicamycin-induced unfolded protein respone. Plant Physiol. 121, 353-361. doi: 10.1104/pp.121.2.353

Komatsu, S., Han, C., Nanjo, Y., Nahar, M. A., Wang, K., He, D., et al. (2013). Labelfree quantitative proteomic analysis of abscisic acid effect in early-stage soybean under flooding. J. Proteome Res. 12, 4769-4784. doi: 10.1021/pr4001898

Komatsu, S., Kobayashi, Y., Nishizawa, K., Nanjo, Y., and Furukawa, K. (2010). Comparative proteomics analysis of differentially expressed proteins in soybean cell wall during flooding stress. Amino Acids 39, 1435-1449. doi: 10.1007/s00726-010-0608-1

Komatsu, S., Kuji, R., Nanjo, Y., Hiraga, S., and Furukawa, K. (2012). Comprehensive analysis of endoplasmic reticulum-enriched fraction in root tips of soybean under flooding stress using proteomics techniques. J. Proteomics 77, 531-560. doi: 10.1016/j.jprot.2012.09.032

Komatsu, S., Nakamura, T., Sugimoto, Y., and Sakamoto, K. (2014). Proteomic and metabolomics analysis of soybean root tips under flooding stress. Protein Peptide Let. 21, 865-884. doi: 10.2174/0929866521666140320110521

Komatsu, S., Wada, T., Abelea, Y., Nouri, M. Z., Nanjo, Y., Nakayama, N., et al. (2009). Analysis of plasma membrane proteome in soybean and application to flooding stress response. J. Proteome Res. 8, 4487-4499. doi: 10.1021/ pr9002883

Kornfeld, R., and Kornfeld, S. (1985). Assembly of asparaginelinked oligosaccharides. Annu. Rev. Biochem. 54, 631-664. doi: 10.1146/annurev.bi.54.070185.003215

Kukavica, B. M., Veljovicc-Jovanovicc, S. D., Menckhoff, L., and Lüthje, S. (2012). Cell wall-bound cationic and anionic class III isoperoxidases of pea root: biochemical characterization and function in root growth. J. Exp. Bot. 63, 4631-4645. doi: 10.1093/jxb/ers139

Lammens, W., Roy, K. L., Schroeven, L., Laere, A. V., Rabijins, A., and Ende, W. V. D. (2009). Structural insights into glycoside hydrolase family 32 and 68 enzymes: functional implications. J. Exp. Bot. 60, 727-740. doi: 10.1093/jxb/ern333

Laxalt, A. M., Cassia, R. O., Sanllorenti, P. M., Madrid, E. A., Andreu, A. B., Daleo, G. R., et al. (1996). Accumulation of cytosolic glyceraldehyde-3-phosphate 
dehydrogenase RNA under biological stress conditions and elicitor treatments in potato. Plant Mol. Biol. 30, 961-972. doi: 10.1007/BF00020807

Lee, A., Nakano, M., Hincapie, M., Kolarich, D., Baker, M. S., Hancock, W. S., et al. (2010). The lectin riddle: glycoproteins fractionated from complex mixtures have similar glycomic profiles. OMICS. 14, 487-499. doi: 10.1089/omi.2010.0075

Ligat, L., Lauber, E., Albenne, C., San Clemente, H., Valot, B., Zivy, M., et al. (2011). Analysis of the xylem sap proteome of Brassica oleracea reveals a high content in secreted proteins. Proteomics 11, 1798-1813. doi: 10.1002/pmic.2010 00781

Liu, J. X., and Howell, S. H. (2010). Endoplasmic reticulum protein quality control and its relationship to environmental stress in plants. Plant Cell 22, 2930-2942. doi: 10.1105/tpc.110.078154

Madera, M., Mann, B., Mechref, Y., and Novotny, M. V. (2008). Efficacy of glycoprotein enrichment by microscale lectin affinity chromatography. J. Sep. Sci. 31, 2722-2732. doi: 10.1002/jssc.200800094

Manavalan, L. P., Guttikonda, S. K., Tran, L. S., and Nguyen, H. T. (2009). Physiological and molecular approaches to improve drought resistance in soybean. Plant Cell Physiol. 50, 1260-1276. doi: 10.1093/pcp/pcp082

McLoughlin, F., Arisz, S. A., Dekker, H. L., Kramer, G., de Koster, C. G., Haring, M. A., et al. (2013). Identification of novel candidate phosphatidic acid-binding proteins involved in the salt-stress response of Arabidopsis thaliana roots. Biochem. J. 450, 573-581. doi: 10.1042/BJ20121639

Michalak, M., Parker, J. M. R., and Opas, M. (2002). $\mathrm{Ca}^{2+}$ signaling and calcium binding chaperones of the endoplasmic reticulum. Cell Calcium 32, 269-278. doi: 10.1016/S0143416002001884

Minic, Z., Jamet, E., Négroni, L., Arsene der Garabedian, P., Zivy, M., and Jouanin, L. (2007). A sub-proteome of Arabidopsis thaliana mature stems trapped on Concanavalin A is enriched in cell wall glycoside hydrolases. J. Exp. Bot. 58, 2503-2512. doi: 10.1093/jxb/erm082

Mohorko, E., Glockshuber, R., and Aebi, M. (2011). Oligosaccharyltransferase: the central enzyme of N-linked protein glycosylation. J. Inherit. Metab. Dis. 34, 869-878. doi: 10.1007/s10545-011-9337-1

Morris, J. A., Dorner, A. J., Edwards, C. A., and Hendershot, L. M. (1997). Immunoglobulin binding protein ( $\mathrm{BiP})$ function is required to protect cells from endoplasmic reticulum stress but is not required for the secretion of selective proteins. J. Biol. Chem. 272, 4327-4334. doi: 10.1074/jbc.272. 7.4327

Nakayama, N., Hashmoto, S., Shimada, S., Takahashi, M., Kim, Y. H., Oya, T., et al. (2004). The effect of flooding stress at the germination stage on the growth of soybean in relation to initialseed moisture content. J. Crop Sci. 73, 323-329. doi: $10.1626 /$ jcs.73.323

Nanjo, Y., Nakamura, T., and Komatsu, S. (2013). Identification of indicator proteins associated with flooding injury in soybean seedlings under label-free quantitative proteomics. J. Proteome Res. 12, 4785-4798. doi: 10.1021/pr40 02349

Nanjo, Y., Skultety, L., Ashraf, Y., and Komatsu, S. (2010). Comparative proteomic analysis of early-stage soybean seedlings responses to flooding by using gel and gel-free techniques. J. Proteome Res. 9, 3989-4002. doi: 10.1021/pr10 $0179 f$

Nanjo, Y., Skultety, L., Uvackova, L., Klubicova, K., Hajduch, M., and Komatsu, S. (2011). Mass spectrometry-based analysis of proteomic changes in the root tips of flooded soybean seedlings. J. Proteome Res. 11, 372-385. doi: $10.1021 /$ pr200701y

Nekrasov, V., Li, J., Batoux, M., Roux, M., Chu, Z. H., Lacombe, S., et al. (2009). Control of the pattern-recognition receptor EFR by an ER protein complex in the plant immunity. EMBO J. 28, 3428-3438. doi: 10.1038/emboj.2009.262

Nishizawa, K., Hiraga, S., Yasue, H., Chiba, M., Tougou, M., Nanjo, Y., et al. (2013). The synthesis of cytosolic ascorbate peroxidases in germinating seeds and seedlings of soybean and their behavior under flooding stress. Biosci. Biotechnol. Biochem. 77, 2205-2209. doi: 10.1271/bbb.130384

Normile, D. (2008). Reinventing rice to feed the world. Science 321, 330-333. doi: 10.1126/science.321.5887.330

Olsen, J. V., de Godoy, L. M. F., Li, G., Macek, B., Mortensen, P., Pesch, R., et al. (2005). Parts per million mass accuracy on an orbitrap mass spectrometer via lock mass injection into a C-trap. Mol. Cell. Proteomics 4, 2010-2021. doi: 10.1074/mcp.T500030-MCP200

Oosterhuis, D. M., Scott, H. D., Hampton, R. E., and Wullschleter, S. D. (1990). Physiological response of two soybean (Glycine max, L. Merr) cultivars to short-term flooding. Environ. Exp. Bot. 30, 85-92. doi: 10.1016/0098-8472(90) 90012-S

Opassiri, R., Pomthong, B., Akiyama, T., Nakphaichit, M., Onkoksoong, T., Cairns, M. K., et al. (2007). A stress-induced rice (Oryza sativa L.) $\beta$-glucosidase represents a new subfamily of glycosyl hydrolase family 5 containing a fascin-like domain. Biochem. J. 408, 241-249. doi: 10.1042/BJ20070734

Ovidio, R. D., Raiola, A., Capodicasa, C., Devoto, A., Potiggia, D., Roberti, S., et al. (2004). Characterization of the complex locus of bean encoding polygalacturonase-inhibiting proteins reveals subfunctionalization for defense against fungi and insects. Plant Physiol. 135, 2424-2435. doi: 10.1104/pp.104.044644

Pan, S., Chen, R., Aebersold, R., and Brentnall, T. A. (2011). Mass spectrometry based glycoproteomics-from a proteomics perspective. Mol. Cell. Proteomics 10:R110.003251. doi: 10.1074/mcp.R110.003251

Parvaiz, A., and Satyawati, S. (2008). Salt stress and phyto biochemical responses of plants. Plant Soil J. 54, 89-99.

Piques, M., Schulze, W. X., Höhne, M., Usadel, B., Gibon, Y., Rohwer, J., et al. (2009). Ribosome and transcript copy numbers, polysome occupancy and enzyme dynamics in Arabidopsis. Mol. Syst. Biol. 5:314. doi: 10.1038/msb.2009.68

Rayon, C., Lerouge, P., and Faye, L. (1998). The protein N-glycosylation in plants. J. Exp. Bot. 49, 1463-1472. doi: 10.1093/jxb/49.326.1463

Roth, Z., Yehezkel, G., and Khalaila, I. (2012). Identification and quantification of protein glycosylation. Int. J. Carbo. Chem. 2012:640923. doi: $10.1155 / 2012 / 640923$

Ruiz-May, E., Thannhauser, T. W., Zhang, S., and Rose, J. K. (2012). Analytical technologies for identification and characterization of the plant $\mathrm{N}$-glycoproteome. Front. Plant Sci. 3:150. doi: 10.3389/fpls.2012.00150

Schmutz, J., Cannon, S. B., Schlueter, J., Ma, J., Mitros, T., Nelson, W., et al. (2010). Genome sequence of the palaeopolyploid soybean. Nature 463, 178-183. doi: 10.1038 /nature 08670

Schwanhäusser, B., Busse, D., Li, N., Dittmar, G., Schuchhardt, J., Wolf, J., et al. (2011). Corrigendum: global quantification of mammalian gene expression control. Nature 7, 126-127. doi: 10.1038/nature11848

Shi, F., Yamamoto, R., Shimamura, S., Hiraga, S., Nakayama, N., Nakamura, T., et al. (2008). Cytosolic ascorbate peroxidase 2 (Capx 2) is involved in the soybean response to flooding. Phytochemistry 69, 1295-1303. doi: 10.1016/j.phytochem.2008.01.007

Sly, W. S., and Fischer, M. D. (1982). The phosphomannosyl recognition system for intracellular and intercellular transport of lysosomal enzymes. J. Cell Biochem. 18, 67-85. doi: 10.1002/jcb.1982.240180107

Spiro, R. G. (2002). Protein glycosylation: nature, distribution, enzymatic formation, and disease implications of glycopeptides bonds. Glycobiology 12, 43-56. doi: $10.1093 /$ glycob/12.4.43R

Tamburino, R., Chambery, A., Parente, A., and Maro, A. D. (2012). A novel polygalacturonase-inhibiting protein (PGIP) from Lathyrus sativus L. seeds. Protein Peptide Lett. 19, 820-825. doi: 10.2174/092986612801619561

Trincone, A., and Giordano, A. (2006). Glycosyl hydrolases and glycosyltransferases in the synthesis of oligosaccharides. Curr. Org. Chem. 31, 1163-1193. doi: 10.2174/138527206777698075

Usadel, B., Nagel, A., Thimm, O., Redestig, H., Blaesing, O. E., Palacios-Rofas, N., et al. (2005). Extension of the visualization tool MapMan to allow statistical analysis of arrays, display of corresponding genes, and comparison with known responses. Plant Physiol. 138, 1195-1204. doi: 10.1104/pp.105. 060459

Vizcaíno, J. A., Côté, R. G., Csordas, A., Dianes, J. A., Fabregat, A., Foster, J. M. et al. (2013). The Proteomics Identifications (PRIDE) database and associated tools: status in 2013. Nucleic Acids Res. 41, D1063-D1069. doi: 10.1093/nar/ gks1262

Voesenek, L. A., Colmer, T. D., Pierik, R., Millenaar, F. F., and Peeters, A. J. (2006). How plants cope with complete submergence. New Phytol. 170, 213-226. doi: 10.1111/j.1469-8137.2006.01692.x

von Schaewen, A., Frank, J., and Koiwa, H. (2008). Role of complex Nglycans in plant stress tolerance. Plant Signal. Behav. 3, 871-873. doi: 10.4161/psb.3.10.6227

Wang, S. B., Shi, Q., Xu, Y., Xie, W. L., Zhang, J., Tian, C., et al. (2012). Protein disulfide isomerase regulates endoplasmic reticulum stress and the apoptic process during prion infection and PrP mutant-induced cytotoxicity. PLoS ONE 7:e38221. doi: 10.1371/journal.pone.0038221 
Yang, Z., and Hancock, W. S. (2004). Approach to the comprehensive analysis of glycoproteins isolated from human serum using a multi-lectin affinity column. J. Chromatogr. A. 1053, 79-88. doi: 10.1016/j.chroma.2004.08.150

Yin, X., Sakata, K., Nanjo, Y., and Komatsu, S. (2014). Analysis of initial changes in the proteins of soybean root tip under flooding stress using gel-free and gel-based proteomic techniques. J. Proteomics 106, 1-16. doi: 10.1016/j.jprot.2014.04.004

Yoshimura, K., Masuda, A., Kuwano, M., Yokota, A., and Akashi, K. (2008). Programmed proteome response for drought avoidance/tolerance in the root of a C3 xerophyte (wild watermelon) under water deficits. Plant Cell Physiol. 49, 226-241. doi: 10.1093/pcp/pcm 180

Zhang, M., Gaschen, B., Blay, W., Foley, B., Haigwood, N., Kuiken, C., et al. (2004). Tracking global patterns of N-linked glycosylation site variation in highly variable viral glycoproteins: HIV, SIV, and HCV envelopes and influenza hemagglutinin. Glycobiology 14, 1229-1246. doi: 10.1093/glycob/cwh106

Zhang, Y., Wen, Z., Washburn, M. P., and Florens, L. (2009). Effect of dynamic exclusion duration on spectral count based quantitative proteomics. Anal. Chem. 81, 6317-6326. doi: 10.1021/ac9004887
Conflict of Interest Statement: The authors declare that the research was conducted in the absence of any commercial or financial relationships that could be construed as a potential conflict of interest.

Received: 03 September 2014; accepted: 22 October 2014; published online: 18 November 2014.

Citation: Mustafa G and Komatsu S (2014) Quantitative proteomics reveals the effect of protein glycosylation in soybean root under flooding stress. Front. Plant Sci. 5:627. doi: $10.3389 / \mathrm{fpls}$.2014.00627

This article was submitted to Plant Proteomics, a section of the journal Frontiers in Plant Science.

Copyright (c) 2014 Mustafa and Komatsu. This is an open-access article distributed under the terms of the Creative Commons Attribution License (CC BY).

The use, distribution or reproduction in other forums is permitted, provided the original author(s) or licensor are credited and that the original publication in this journal is cited, in accordance with accepted academic practice. No use, distribution or reproduction is permitted which does not comply with these terms. 